\title{
Multi-drug resistant facultative pathogenic bacteria colonizing the vagina of pregnant women with premature rupture of membrane, Tanzania
}

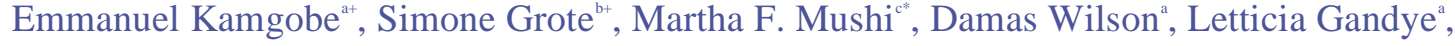 \\ Oliver Bader ${ }^{\mathrm{b}}$, Stephen E. Mshana ${ }^{\mathrm{ct}}$, Uwe Gro $\beta^{\mathrm{b}, \mathrm{d}+}$

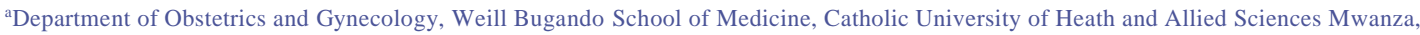 \\ Tanzania; \\ b Institute of Medical Microbiology, Goettingen University Medical Centre, Germany; \\ ${ }^{\mathrm{c}}$ Department of Microbiology and Immunology, Weill Bugando School of Medicine, Catholic University of Heath and Allied Sciences Mwanza, \\ Tanzania; \\ ${ }^{\mathrm{d} G o e t t i n g e n ~ I n t e r n a t i o n a l ~ H e a l t h ~ N e t w o r k ~}$ \\ + Equal contributions \\ *Correspondence to Martha F. Mushi (mushimartha@gmail.com)
}

\section{ABSTRACT}

Background: Premature rupture of membrane (PROM) contributes to approximately one-third of premature birth and $10 \%$ perinatal mortality worldwide. Here, we report the patterns of facultative pathogenic bacteria colonizing the vagina of pregnant women to guide prophylactic antibiotic treatment in the management of PROM.

Methods: This comparative cross-sectional study was conducted between August 2015 and March 2016. High vaginal swabs were collected and processed to detect the presence of facultative pathogenic bacteria. Isolate identification and antibiotic susceptibility testing was conducted using MALDI-TOF MS and VITEK-2 system, respectively. Data were analyzed using STATA version 13.

Results: A total of 175 pregnant women with PROM and 175 without PROM were investigated. The median age of the pregnant women with PROM was significantly higher than that of pregnant women without PROM: 27 [21-32] vs. 25[21-29], $\mathrm{p}=0.026$. Pregnant women with PROM were significantly more likely to be colonized with facultative pathogenic bacteria 59/175 (33.7\%), 95\% CI; 26.7-40.7 than pregnant women without PROM; 27/175 (15.4\%), 95\% CI; 10.1-20.7, P<0.001. Escherichia coli were significantly more isolated from pregnant women with PROM than those without PROM: $36(73.5 \%)$ vs. $13(26.5 \%), \mathrm{p}<0.001$. The proportion of resistance among pathogenic isolates from women with PROM to ampicillin, trimethoprim/sulfamethoxazole and cefotaxime were $100 \%, 66.7 \%$ and $40 \%$, respectively.

Conclusions: The vagina of pregnant women with PROM is significantly more colonized by multi-resistant facultative pathogenic bacteria than that of pregnant women without PROM. Further studies should be done to elucidate the impact of these bacteria in relation to PROM and the pregnancy outcome.

Key words: Vaginal colonization, facultative pathogenic bacteria, pregnancy, premature rupture of membrane, multi drug resistance

\section{INTRODUCTION}

W orldwide, premature rupture of membranes (PROM) among pregnant women has been found to range from $3.3 \%$ to $10 \%$, with $80 \%$ of them occurring at term ${ }^{1,2}$. PROM leads to the loss of the natural protection of the fetus hence posing a threat to bacterial infections ${ }^{3}$. In addition, PROM is highly associated with the increased pregnancy complications such as preterm labor, fetal demise, respiratory distress syndrome, neonatal sepsis, umbilical cord prolapse, postpartum endometritis, disseminated intravascular coagulopathy (DIC) and chorioamnionitis ${ }^{1,4}$. The pathogenesis of PROM has been linked to the isolation of facultative 
pathogenic bacteria in the vagina ${ }^{5-8}$, there is a strong association between pathogens colonizing the vagina and subsequent chorioamnionitis. Bacteria and protozoan parasites (Trichomonas vaginalis) secrete proteases and other factors that degrade the collagen and weaken the fetal membrane ${ }^{9,10}$. Furthermore, host inflammatory responses due to pathogenic bacteria can induce the production of prostaglandin which can lead to uterine irritability and membrane collagen degradation hence increasing the risk of PROM $^{8,11}$.

In developing countries, Escherichia coli, Klebsiella pneumoniae, Group B Streptococcus (GBS), Staphylococcus aureus and Streptococcus pyogenes have been found to be the commonest facultative pathogenic bacteria colonizing the vagina and implicated in PROM ${ }^{5-}$ 7,12. These pathogenic bacteria have also been implicated in chorioamnionitis ${ }^{13,14}$. Despite $12 \%$ contribution of the PROM to antenatal hospital admissions in East Africa ${ }^{15}$ and black women being reported to have the highest risk of being colonized by the potential pathogenic bacteria ${ }^{16}$, the spectrum of the respective bacteria colonizing the vagina of pregnant women with and without PROM in East Africa is not well understood.

A previous study ${ }^{17}$ in Uganda among pregnant women with PROM, noted the resistance to most commonly used antibiotics such as ceftriaxone, ampicillin, trimethoprim/sulfamethoxazole and erythromycin was high with good susceptibility to expensive antibiotics such as vancomycin and meropenem. The World Health Organization (WHO) recommends the use of antibiotic prophylaxis among pregnant women with $\operatorname{PROM}^{18}$. Different regimen involving penicillin and erythromycin have been recommended. However, number of factors should be assessed such as population of women to be offered antenatal prophylactic antibiotics and types of antibiotics to be used. With increase antibiotic resistance among the pathogens involved in PROM local susceptibility data are crucial in establish empiric treatment protocol with emphasis on the individual tailored treatment. This comparative cross-sectional study was designed to investigate the patterns of facultative pathogenic bacteria colonizing pregnant women with and without PROM and their antimicrobial susceptibility.

\section{METHODS}

Study design, area, and population

The comparative cross-sectional study was conducted between August 2015 and March 2016 at Bugando Medical Centre (BMC), Sekou Toure Regional Hospital, Nyamagana District Hospital and Buzuruga Health Center in the city of Mwanza, Tanzania. The selected hospital are the highly populated faith base and government hospital which cover large percentage of the Mwanza population. Bugando Medical Centre is the tertiary consultant teaching hospital of Catholic University of Health and Allied Sciences with bed capacity of 900. Sekou Toure Regional Referral hospital is located in Ilemela district with bed capacity of 375 serving the all referrals from six district hospitals of Mwanza region. While Nyamagana District hospital has maternity bed capacity of 30 and Buzuruga health center has maternity ward with a bed capacity of 15 . The study involved all pregnant women with gestation age of 36 weeks and above with and without PROM during the study period.

Sampling, inclusion, and exclusion criteria Using Kirkwood formula for comparative studies ${ }^{19}$ and assumption of the $10 \%$ effect size by the prevalence obtained in the previous study ${ }^{12}$, the minimum sample size obtained was 350 pregnant women (175 pregnant women with and 175 pregnant women without PROM). The pregnant women with and without PROM were recruited serially until the sample size was reached. The study excluded all pregnant women with cervical incompetency, polyhydramnios, mal-presentation, multiple pregnancies, fever, abdominal pain, foul smelling per vaginal leakage and history of antibiotic therapy in the past two weeks prior to the study to minimize the bias in relation to the colonization of the facultative bacteria. In the current study, pathogenic bacteria were defined as bacteria which are potentially capable of causing clinical infections in the genital urinary $\operatorname{tract}^{20}$.

Sample collection and laboratory procedures:

By the use of sterile Cusco speculum, cervix was exposed, and high vaginal swab was taken using a sterile swab. The swabs were transported to the microbiology laboratory using Stuart transport media (HiMedia, India) within 2 hours of collection. All swabs were cultured on the 5\% sheep blood agar (BA) and MacConkey agar (MCA) (Oxoid, UK) and aerobically incubated at $37^{\circ} \mathrm{C}$ for $24-48$ hours. Identification to species level was done by matrixassisted laser desorption ionization-time of flight (MALDI-TOF) mass spectrometry (Bruker Daltonics, Germany) on extracted cells as previous described ${ }^{21,22}$. Only facultative pathogenic bacteria were included for statistical analysis and subsequent antimicrobial susceptibility testing. Potential contaminants, e.g. $S$. epidermidis, Bacillus spp., were excluded. The current study mainly concentrated on the antibiotics that are recommended for PROM management. The tested antibiotics included: ampicillin (AMP), trimethoprim/sulfamethoxazole, (SXT), ciprofloxacin (CIP), Gentamicin (CN), ceftazidime (CAZ), ceftriaxone 
(CRO) and meropenem (MRP) (Oxoid, UK). Antimicrobial susceptibility testing was done using VITEK-2 system (bioMérieux, France) and interpreted as per

EUCAST

(http://www.eucast.org/clinical breakpoints/) guidelines. Using excel sheet, data were double entered, cleaned and transferred to STATA version 11 for analysis. Categorical variables such as residence, marital status, education, occupation, gravidity, history of PROM, number of antenatal care (ANC) visit, presence or absence of PROM and positive or negative bacterial growth were summarized as proportions. Continuous data (age, gestation age and parity) were summarized using median and inter quartile range. The statistical significance was set at a $p$ value of less than 0.05. Two-sample test of proportions was used to compare the pattern of facultative pathogenic bacteria colonization among pregnant women with PROM and those without PROM.

\section{Ethics approval and consent to participate}

The joint CUHAS/BMC research ethics and review committee granted ethical clearance with certificate number CREC/096/2015. Permission to conduct the study was sought from all hospital administrations. All patients were requested to sign a written informed consent before recruitment was done.

\section{RESULTS}

\section{Demographic characteristic}

A total of 350 pregnant women (175 with PROM and 175 without PROM) were enrolled and analyzed. The majority of studied women resided in urban areas $286(81.7 \%$ ) and had primary school education $185(52.9 \%)$. The median age of pregnant women was 26 [21-31] years. The median age of pregnant women with PROM was significantly higher than pregnant women without PROM 27 [21-32] vs. 25 [21-29], $\mathrm{p}=0.026$ (Table 1).

The median gestation age of pregnant women at the time of enrollment was 38[36-40] weeks for pregnant women with PROM and 38[37-39] for pregnant women without PROM. History of PROM in previous pregnancy was higher among pregnant women with PROM than pregnant women without PROM 20 (11.4\%) vs. 6 (3.4\%), $\mathrm{p}=0.004$. In addition, history of preterm birth in the previous pregnancy was higher among pregnant women with PROM than those without PROM 16(72.7\%) vs. 6 (27.3\%), $\mathrm{p}=0.026$. Regarding antenatal visits, high proportion of pregnant women with PROM had more than 4 antenatal visits compared to pregnant women without PROM 92 (52.6\%) vs. 54 (30.9\%), p< 0.001 (Table 1).

\section{Bacterial colonization pattern}

Of 350 women screened, 86 (24.6\%) were colonized with facultative pathogenic bacteria. Pregnant women with PROM were significantly more often colonized with facultative pathogenic bacteria 59/175 (33.7\%), 95\% CI; 26.7-40.7 than pregnant women without PROM 27/175 (15.4\%), 95\% CI; 10.1-20.7, p<0.001. The most frequently isolated bacteria were Escherichia coli 49(39.2\%) and Pseudomonas spp. 22(17.6\%). E. coli isolates were significantly more from pregnant women with PROM than those without PROM, 36 (73.5\%) vs. 13 (26.5\%), $\mathrm{p}<0.001$ (Table 2). Of 175 pregnant women with PROM, 13(7.4\%) had double colonization with two different species of facultative pathogenic bacteria. All pathogenic bacteria isolated from pregnant women with PROM were resistant to ampicillin, while those isolated from pregnant women without PROM were 92.6\% (25/26) resistant to ampicillin. The proportion of resistant bacteria from women with PROM to ampicillin, trimethoprim/sulfamethoxazole and cefotaxime were $57(100 \%), 46(66.7 \%)$ and 28(40\%), respectively while for women without PROM the proportion was $25(96.2 \%)$, 21(52.5\%) and 20(48.8\%), respectively Table 3. E. coli isolates from pregnant women with PROM were significantly more resistant to trimethoprim/sulphamethoxazole than $E$. coli isolates from women without PROM 82.9\% (29/35) vs. 58.3\% (7/12), p<0.001 Figure 1. One E. coli isolate from pregnant woman with PROM was resistant to all antibacterial agents tested (ampicillin, ciprofloxacin, gentamycin, trimethoprim/sulphamethoxazole, ceftriaxone, ceftazidime, cefotaxime, ertapenem, meropenem). 
Multi-drug resistant facultative pathogenic bacteria colonizing vaginal

TABLE 1. Socio-demographic and clinical data of 350 pregnant women studied

\begin{tabular}{|c|c|c|c|c|}
\hline $\begin{array}{l}\text { Patient } \\
\text { characteristic }\end{array}$ & $\begin{array}{c}\text { Total } \\
\mathbf{n}=\mathbf{3 5 0}(\%)\end{array}$ & $\begin{array}{c}\text { PROM } \\
\mathrm{n}=175(\%)\end{array}$ & $\begin{array}{l}\text { Non-PROM } \\
n=175(\%)\end{array}$ & $p$-value \\
\hline Age $*$ years & $26[21-31]$ & 27 [21-32] & $\begin{array}{ll}25 & {[21-29]}\end{array}$ & 0.026 \\
\hline \multicolumn{5}{|l|}{ Residence } \\
\hline Urban & $286(81.7)$ & $131(74.86)$ & $155(88.6)$ & \\
\hline Rural & $64 \quad(18.3)$ & $44 \quad(25.14)$ & 20 (11.4) & 0.001 \\
\hline \multicolumn{5}{|l|}{ Marital status } \\
\hline Single & $73(20.85)$ & $46 \quad(26.3)$ & 27 (15.44) & \\
\hline Married & $277(79.15)$ & $129(73.7)$ & $148(84.57)$ & 0.013 \\
\hline \multicolumn{5}{|l|}{ Education } \\
\hline Primary & $185(52.85)$ & $91 \quad(52)$ & $89 \quad(50.9)$ & \\
\hline Secondary & $123(35.14)$ & $68 \quad(38.9)$ & $55 \quad(31.4)$ & \\
\hline University & 42 (12) & $16(9.14)$ & 31 (17.7) & 0.071 \\
\hline \multicolumn{5}{|l|}{ Gravidity } \\
\hline Prime & $100(28.6)$ & $36 \quad(20.6)$ & $64 \quad(36.6)$ & \\
\hline Gravid 2 & $175(50.0)$ & $86 \quad(49.0)$ & $89 \quad(50.9)$ & \\
\hline Multigravida & 75 (21.4) & $53 \quad(30.3)$ & 22 (12.6) & $<0.001$ \\
\hline GA* weeks & 38 [36-40] & $38 \quad[36-40]$ & 38 [37-39] & 0.012 \\
\hline \multicolumn{5}{|l|}{ PROM before } \\
\hline No & $324(92.6)$ & $155(88.6)$ & 169 (96.6) & \\
\hline Yes & $26(7.4)$ & $20 \quad(11.4)$ & $6(3.4)$ & 0.004 \\
\hline $\begin{array}{l}\text { GA at } \\
\text { booking* }\end{array}$ & 20 [18-22] & 20 [18-22] & 20 [18-22] & 0.236 \\
\hline \multicolumn{5}{|l|}{ ANC visit } \\
\hline Below 4 & 79 (22.6) & $29(16.6)$ & $50 \quad(28.6)$ & \\
\hline 4 & $125(35.7)$ & $54 \quad(30.9)$ & 71 (40.6) & \\
\hline Above 4 & $146(41.7)$ & 92 (52.6) & $54 \quad(30.9)$ & $<0.001$ \\
\hline
\end{tabular}

GA is gestation age, * Are variables were median is the measure of central tendency

TABLE 2. Vaginal pathogenic bacteria colonizing 350 pregnant women in Mwanza

\begin{tabular}{llll}
\hline BACTERIA & PROM N (\%) & Non-PROM N (\%) & p- value \\
\hline E. coli (49) & $36(73.5)$ & $13(26.5)$ & $<0.001$ \\
Pseudomonas spp. $(22)$ & $12(54.6)$ & $10(45.5)$ & 0.273 \\
K. pneumoniae (17) & $11(64.7)$ & $6(35.3)$ & 0.043 \\
Enterobacter spp. $(13)$ & $8(61.5)$ & $5(38.5)$ & 0.119 \\
Pathogenic GPB* (10) & $9(90)$ & $1(10)$ & 0.002 \\
Acinetobacter spp. $(7)$ & $1(14.3)$ & $6(85.7)$ & 0.0038 \\
Other GNB* (7) & $5(71.4)$ & $2(28.6)$ & 0.054 \\
Total (125) & $82(65.6)$ & $40(34.4)$ & $<0.001$ \\
\hline
\end{tabular}

*Pathogenic GPB stands for pathogenic gram-positive bacteria which include $S$. aureus, S. haemolyticus, E. faecalis and S. saprophyticus and other GNB stands for other gram-negative bacteria which include Proteus spp., Morganella morganii and Escherichia hermannii. 
Multi-drug resistant facultative pathogenic bacteria colonizing vaginal of pregnant women

TABLE 3. Antimicrobial resistance pattern among vagina pathogenic bacteria isolates

\begin{tabular}{lllll}
\hline & \multicolumn{2}{c}{ PROM } & \multicolumn{2}{c}{ Non-PROM } \\
\cline { 2 - 3 } Antibiotic & Tested & Resistant $(\%)$ & Tested & Resistant (\%) \\
\hline Ampicillin & 57 & $57(100)$ & 26 & $25(96.2)$ \\
Ciprofloxacin & 69 & $22(31.9)$ & 41 & $7(17.1)$ \\
Gentamycin & 69 & $16(23.2)$ & 41 & $8(19.5)$ \\
SXT* & 69 & $46(66.7)$ & 40 & $21(52.5)$ \\
Ceftriaxone & 57 & $14(24.6)$ & 22 & $3(13.6)$ \\
Ceftazidime & 70 & $17(24.3)$ & 40 & $9(22.5)$ \\
Cefotaxim & 70 & $28(40)$ & 41 & $20(48.8)$ \\
Ertapenem & 57 & $1(1.8)$ & 26 & $1(4)$ \\
Imipenem & 68 & $3(4.4)$ & 41 & $0(0.0)$ \\
Meropenem & 68 & $2(2.9)$ & 41 & $0(0.0)$ \\
\hline
\end{tabular}

*SXT: trimethoprim/sulphamethaxazole

FIGURE 1: Antibacterial resistance pattern of E. coli colonizing vagina of pregnant women with and without premature rupture of membrane

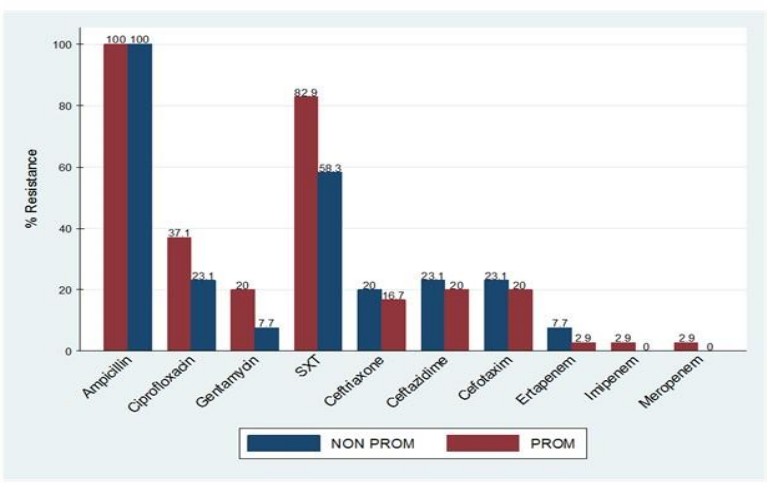

*SXT: trimethoprim/sulphamethaxazole 


\section{DISCUSSION}

Premature rupture of the membrane (PROM) contributes to approximately one third of premature births ${ }^{2,23,24}$, and approximately $10 \%$ of perinatal mortality ${ }^{25}$. A significant proportion of pregnant women with PROM in the current study had history of PROM and premature delivery in the previous pregnancy. This has also been reported elsewhere ${ }^{26}$, ${ }^{27}$ and could be due to the possibility of the pregnant woman genetic defect in collagen synthesis that can affect the structure and function of the fibrillar collagens ${ }^{28}$. The weakening of the connective tissue by the enzymatic depolarization of the collagen fibers in fetal membrane can also explain the observed findings ${ }^{29,30}$. Women with PROM in the current study were significantly older than those without PROM pointing to the possibility of age-dependent collagen synthesis $^{31}$. However, there is no documentation of the influence of age and facultative pathogenic bacteria colonizing vagina during the reproductive age. The age has been found to influence normal flora before puberty and after menopause $\mathrm{e}^{32,33 \text {. }}$

Vaginal colonization with facultative pathogenic bacteria was significantly more often observed in pregnant women with PROM than in pregnant women without PROM. This has also been reported in previous studies in Tanzania and India ${ }^{12,25}$. Bacteria in the vagina have been found to secrete enzymes that can either degrade the fetal membranes or increase production of prostaglandins ${ }^{4,12,34-39}$ high concentration of prostaglandins can stimulate the uterine contractions leading to the membrane rupture. This is further supported by the fact that the presence of pathogenic bacteria has been associated with chorion thinning among PROM pregnant women ${ }^{40 .}$

As it was also previously reported in Tanzania and India ${ }^{12,41}$, E. coli and Pseudomonas spp. were the commonest bacteria detected. This could partly be explained by the fact that these pathogens belong to the normal flora of the gastrointestinal tract and might therefore be present in perineum with increased chance to colonize the genital tract. Staphylococcus aureus was the commonest gram-positive bacterial species detected among pregnant women with PROM in this study. Similar observations were made previously ${ }^{12} 25$. Detection of S. aureus colonizing women with PROM has been linked with other factors like urinary tract infections and bacterial vaginosis ${ }^{25}$, these factors were not investigated in the current study.

Bacteria isolated from pregnant women with PROM were more resistant to ampicillin and trimethoprim/sulfamethoxazole. Similar results have been reported in other studies from pregnant women ${ }^{42,43}$ and postdelivery women in similar settings ${ }^{44}$. This could partly be explained by the fact that ampicillin and trimethoprim/sulfamethoxazole are the commonest class of antibiotic in use in the study settings. Despite the fact that this study has clearly demonstrated the significant differences in patterns of bacteria colonizing pregnant women with PROM and those without PROM, neonatal outcomes which could give more evidence on the association of vagina colonization of the facultative pathogenic bacteria and clinical fetal infections especially for the pregnant women with PROM were not recorded. Furthermore, the presence of Candida species were not assessed, this has been recommended for future studies.

In conclusion, vagina of pregnant women with PROM was more colonized by multi-resistant facultative pathogenic bacteria than the one of pregnant women without PROM. Escherichia coli strains were the commonest pathogenic bacteria and were highly resistant to ampicillin and trimethoprim/sulphamethoxazole. Further studies should be done to elucidate the impact of these pathogens in relation to PROM and the pregnancy outcome. There is a need to adjust the empirical prophylaxis treatment of PROM based on the local susceptibility profile.

Acknowledgement: We thank member of the Department of Obstetrics and Gynecology, Microbiology and Immunology and Institute of Medical Microbiology Gottingen for their technical support. All authors have declared no conflict of interest in publishing this work.

Disclosure: None declared.

\section{REFERENCES}

1. Tavassoli F, Ghasemi M, Mohamadzade A, F T, S J, editors. (Survey of Pregnancy Outcome in Preterm Premature Rupture of Membranes with Amniotic Fluid Index $<5$ and $\geq 5$ ). omjournal; 2010: Mashhad university of medical sciences

2. Mercer BM, Miodovnik M, Thurnau GR, Goldenberg RL, Das AF, Ramsey $\mathrm{RD}$, et al. Antibiotic therapy for reduction of infant morbidity after preterm premature rupture of the membranes: a randomized controlled trial. Jama. 1997;278(12):989-95.

3. Poma PA. Premature rupture of membranes. Journal of the National Medical Association. 1996;88(1):27.

4. Donati L, Di Vico A, Nucci M, Quagliozzi L, Spagnuolo T, Labianca A, et al. Vaginal microbial flora and outcome of pregnancy. Archives of gynecology and obstetrics. 2010;281(4):589-600.

5. McDonald HM, O'Loughlin JA, Jolley PT, Vigneswaran R, McDonald PJ. Changes in vaginal flora during pregnancy and association with preterm birth. Journal of Infectious Diseases. 1994;170(3):724-8.

6. Regan J, Chao S, James L. Premature rupture of membranes, preterm delivery, and group B streptococcal colonization of mothers. American journal of obstetrics and gynecology. 1981;141(2):184-6.

7. EKWO EE, GOSSELINK CA, WOOLSON R, MOAWAD A. Risks for premature rupture of amniotic membranes. International Journal of Epidemiology. 1993;22(3):495-503.

8. McGregor JA, French JI, Parker R, Draper D, Patterson E, Jones W, et al. Prevention of premature birth by screening and treatment for common genital tract infections: results of a prospective controlled evaluation. American journal of obstetrics and gynecology. 1995;173(1):157-67.

9. McGREGOR JA, FRENCH JI, TODD JK, LAWELLIN D, FRANCO-BUFF A, SMITH C. Bacterial Protease-Induced Chorioarnnio tic Membrane Reduction of Strength and Elasticity. Obstetrics \& Gynecology. 1987;69(2):167-74. 
10. Draper D, Jones W, Heine RP, Beutz M, French JI, McGregor JA. Trichomonas vaginalis weakens human amniochorion in an in vitro model of premature membrane rupture. Infectious diseases in obstetrics and gynecology. 1995;2(6):267-74.

11. McGregor J, Schoonmaker J, Lunt B, Lawellin D. Antibiotic inhibition of bacterially induced fetal membrane weakening. Obstetrics \& Gynecology. 1990;76(1): 124-8.

12. August $F$. The microbial pattern associated with preterm premature rupture of membranes as seen at Muhimbili National Hospital: Muhimbili University of Health and Allied Sciences; 2007.

13. Sherman D, Tovbin J, Lazarovich T, Avrech O, Reif R, Hoffmann S, et al. Chorioamnionitis caused by gram-negative bacteria as an etiologic factor in preterm birth. European Journal of Clinical Microbiology and Infectious Diseases. 1997;16(6):417-23.

14. Martius J, Eschenbach D. The role of bacterial vaginosis as a cause of amniotic fluid infection, chorioamnionitis and prematurity-a review. Archives of gynecology and obstetrics. 1990;247(1):1-13.

15. Nakubulwa S, Kaye DK, Bwanga F, Tumwesigye NM, Mirembe FM Genital infections and risk of premature rupture of membranes in Mulago Hospital, Uganda: a case control study. BMC research notes. 2015;8(1):573.

16. Goldenberg RL, Klebanoff MA, Nugent R, Krohn MA, Hillier S, Andrews WW. Bacterial colonization of the vagina during pregnancy in four ethnic groups. American Journal of Obstetrics \& Gynecology. 1996;174(5):1618-21.

17. Musaba MW, Kagawa MN, Kiggundu C, Kiondo P, Wandabwa J. Cervicovaginal bacteriology and antibiotic sensitivity patterns among women with premature rupture of membranes in Mulago Hospital, Kampala, Uganda: A cross-sectional study. Infectious diseases in obstetrics and gynecology. 2017;2017.

18. WHO Recommendation on the prophylactic antibiotic of choice in women with preterm prelabour rupture of membranes. The WHO reproductive Health Library November 2015

19. Kirkwood B, Sterne J. Calculation of required sample size. London: Blackwells Science Limited. 1988.

20. Ronald AR, Alfa MJ. Microbiology of the genitourinary system. 1996

21.Wieser A, Schneider L, Jung J, Schubert S. MALDI-TOF MS in microbiological diagnostics - identification of microorganisms and beyond (mini review). Applied microbiology and biotechnology. 2012;93(3):965-74.

22. Bader O, Weig M, Taverne-Ghadwal L, Lugert R, Gross U, Kuhns M. Improved clinical laboratory identification of human pathogenic yeasts by matrix-assisted laser desorption ionization time-of-flight mass spectrometry. Clinical Microbiology and Infection. 2011;17(9):1359-65.

23. Kaya D. Risk factors of preterm premature rupture of membranes at Mulago hospital Kampala. East African medical journal. 2001;78(2):65-9.

24. Eleje GU, Adinma JI, Ghasi S, Ikechebelu JI, Igwegbe AO, Okonkwo JE, et al. Antibiotic susceptibility pattern of genital tract bacteria in pregnant women with preterm premature rupture of membranes in a resource-limited setting. International Journal of Gynecology \& Obstetrics. 2014;127(1):10-4.

25. Karat C, Madhivanan P, Krupp K, Poornima S, Jayanthi N, Suguna J, et al. The clinical and microbiological correlates of premature rupture of membranes. Indian journal of medical microbiology. 2006;24(4):283.

26. Doody D, Patterson M, Voigt L, Mueller B. Risk factors for the recurrence of premature rupture of the membranes. Paediatric and perinatal epidemiology. 1997;11(S1):96-106.

27. Ladfors L, Mattsson L-A, Eriksson M, Milsom I. Prevalence and risk factors for prelabor rupture of the membranes (PROM) at or near term in an urban Swedish population. Journal of perinatal medicine. 2000;28(6):491-6.

28.Anum EA, Hill LD, Pandya A, Strauss J. Connective tissue and related disorders and preterm birth: clues to genes contributing to prematurity. Placenta. 2009;30(3):207-15

29.Bourne G. The foetal membranes: a review of the anatomy of normal amnion and chorion and some aspects of their function. Postgraduate medical journal. 1962;38(438): 193 .

30.Strauss JF. Extracellular matrix dynamics and fetal membrane rupture. Reproductive Sciences. 2013;20(2):140-53.

31.Varani J, Dame MK, Rittie L, Fligiel SE, Kang S, Fisher GJ, et al. Decreased collagen production in chronologically aged skin: roles of age-dependen alteration in fibroblast function and defective mechanical stimulation. The American journal of pathology. 2006;168(6):1861-8.
32.Cauci S, Driussi S, De Santo D, Penacchioni P, Iannicelli T, Lanzafame P, et al. Prevalence of bacterial vaginosis and vaginal flora changes in peri-and postmenopausal women. Journal of clinical microbiology. 2002;40(6):2147-

33.Burton JP, Reid G. Evaluation of the bacterial vaginal flora of 20 postmenopausal women by direct (Nugent score) and molecular (polymerase chain reaction and denaturing gradient gel electrophoresis) techniques. Journal of Infectious Diseases. 2002;186(12):1770-80.

34. Yudin MH, Money DM. Screening and management of bacterial vaginosis in pregnancy. Journal of obstetrics and gynaecology Canada: JOGC $=$ Journal d'obstetrique et gynecologie du Canada: JOGC. 2008;30(8):702-16.

35.Jones F, Miller G, Gadea N, Meza R, Leon S, Perez J, et al. Prevalence of bacterial vaginosis among young women in low-income populations of coastal Peru. International journal of STD \& AIDS. 2007;18(3):188-92.

36.Baisley K, Changalucha J, Weiss HA, Mugeye K, Everett D, Hambleton I, et al. Bacterial vaginosis in female facility workers in north-western Tanzania: prevalence and risk factors. Sexually transmitted infections. 2009;85(5):370-

37. Shayo PA, Kihunrwa A, Massinde AN, Mirambo M, Rumanyika RN,Ngwalida N, et al. Prevalence of bacterial vaginosis and associated factors among pregnant women attending at Bugando Medical Centre, Mwanza, Tanzania. Tanzania journal of health research. 2012;14(3).

38.Epstein FH, Parry S, Strauss JF. Premature rupture of the fetal membranes. New England Journal of Medicine. 1998;338(10):663-70.

39. Novy MJ, McGregor JA, Iams JD. New perspectives on the prevention of extreme prematurity. Clinical obstetrics and gynecology. 1995;38(4):790808.

40.Fortner B, Grotegut CA, Ransom CE, Bentley RC, Feng L, Lan L, et al. Bacteria localization and chorion thinning among preterm premature rupture of membranes. PloS one. 2014;9(1):e83338.

41.Kerur BM, Bhat BV, Harish B, Habeebullah S, Kumar CU. Maternal genital bacteria and surface colonization in early neonatal sepsis. The Indian Journal of Pediatrics. 2006;73(1):29-32.

42.Masinde A, Gumodoka B, Kilonzo A, Mshana S. Prevalence of urinary tract infection among pregnant women at Bugando Medical Centre, Mwanza, Tanzania. Tanzania journal of health research. 2009;11(3)

43.Chaula T, Seni J, Ng'walida N, Kajura A, Mirambo MM, DeVinney R, et al. Urinary Tract Infections among HIV-Positive Pregnant Women in Mwanza City, Tanzania, Are High and Predicted by Low CD4. International journal of microbiology. 2017;2017.

44. Nelson E, Kayega J, Seni J, Mushi MF, Kidenya BR, Hokororo A, et al. Evaluation of existence and transmission of extended spectrum beta lactamase producing bacteria from post-delivery women to neonates at Bugando Medical Center, Mwanza-Tanzania. BMC research notes. 2014;7(1):1.

\section{Peer Reviewed}

Competing Interests: None declared

Received: 14 Jan 2020; Accepted: 3 Apr 2020.

Cite this article as: Kamgobe E, Grote S, Mushi MF, Wilson D, Gandye L, Bader O, Mshana SE, Gro $\beta$ U. Multi-drug resistant facultative pathogenic bacteria colonizing vaginal of pregnant women with premature rupture of membrane, Tanzania. E Afr Sci. 2020;1(2):29-35. http://doi.org/10.24248/EASci-D-20-00001

(C) Kamgobe et al. This is an open-access article distributed under the terms of the Creative Commons Attribution License, which permits unrestricted use, distribution, and reproduction in any medium, provided the original author and source are properly cited. To view a copy of the license, visit http://creativecommons.org/licens- es/by/4.0/. When linking to this article, please use the following permanent link: http://doi.org/10.24248/EASci-D-20-00001 